\title{
Predictors of mortality and disability in stroke
}

\author{
K SHEIKH, ${ }^{1 *}$ P J BRENNAN, ${ }^{1}$ T W MEADE, ${ }^{1}$ D S SMITH,${ }^{2} \dagger$ ANDE GOLDENBERG ${ }^{2}$ \\ From the MRC Epidemiology and Medical Care Unit, ${ }^{1}$ and the Department of Rheumatology and \\ Rehabilitation, ${ }^{2}$ Northwick Park Hospital, Harrow, UK
}

SUMMARY The increasingly accurate prediction of survival and functional recovery in patients with stroke will be of value in planning both their individual management and the health and social services needed. To establish the independent predictive effects of a range of personal and clinical characteristics, data on 900 patients admitted to Northwick Park Hospital with stroke were analysed by stepwise multiple regression. Older patients who lose consciousness at the outset and show signs of multiple neurological deficits, abnormal pupils, and conjugate deviation of the eyes are more likely to die within a year than those without these characteristics. Those who survive the acute episode and are discharged alive are more likely to die within a year if they are old and have sensory loss with severe physical disability. Older female patients who are incontinent, lose consciousness at the onset of stroke, sustain extensive motor deficits in combination with other neurological deficits, and have residual disabilities from previous strokes are particularly likely to be severely disabled on discharge from hospital. Routinely collected clinical data enable useful forecasts about mortality and disability after stroke. The accuracy of these forecasts can probably be improved further.

Several characteristics have been shown to indicate prognosis for survival and functional recovery after stroke. ${ }^{1-8}$ These include age; motivation; site, type, and side of lesion; level of consciousness; paralysis of conjugate gaze; abnormalities of pupillary reflexes; motor, sensory, and speech impairments, alone or in combination; dementia and incontinence; and other serious diseases besides stroke. Hearer ${ }^{9}$ reported that homonymous hemianopia adversely influences prognosis, but Oxbury $e^{2} a^{8}$ did not confirm this. It is generally acknowledged that many of the characteristics in question are associated with one another. Most studies have used univariate methods of analysis, though some have grouped several variables together as predictors of outcome. ${ }^{18-10}$ Only three studies appear to have used formal multivariate methods. Rabkin et $\mathrm{ll}^{11}$ used a multiple logistic function to show the separate effects of age, blood pressure, and previous ischaemic heart disease on five-year survival, but they and Bourestom ${ }^{12}$ studied only 52 and 53 patients respectively. Anderson $e a l^{13}$ studied improvement in self-care and communication in 255 selected patients and found that perceptual loss, behavioural changes, previous stroke, nystagmus, hypotension, and prolonged unconsciousness each adversely affected the outcome.
We present multivariate analyses of several possible predictors of mortality at three weeks and a year, and of early disability, in 900 patients with stroke. These analyses enable a more detailed evaluation than hitherto of the independent contribution to prognosis of a range of characteristics.

\section{Methods}

The study population consisted of all patients admitted to Northwick Park Hospital from October 1972 to September 1977 with a confirmed diagnosis of recent stroke, or those who had had a stroke during the same five-year period while in hospital for some other illness. Stroke was defined as an acute disturbance of cerebral function of presumed vascular origin resulting in focal neurological deficit, but for the purpose of this study patients with transient cerebral ischaemia and subarachnoid haemorrhage or those with intracranial tumours presenting as stroke were excluded. Data on medical history, clinical findings, and residual disability were obtained from the case notes after discharge from hospital. All those discharged alive were traced a year after the stroke, and mortality data were obtained from the hospital records or general practitioners.

"Present address: Department of Epidemiology, University of Michigan School of Public Health, Ann Arbor, Michigan 48109, USA.

†Present address: Department of Rehabilitation, Flinders University Medical Centre, Bedford Park, S Australia 5042. 
Table 1 Relationship of 32 independent variables with mortality or disability (dependent variables) or both

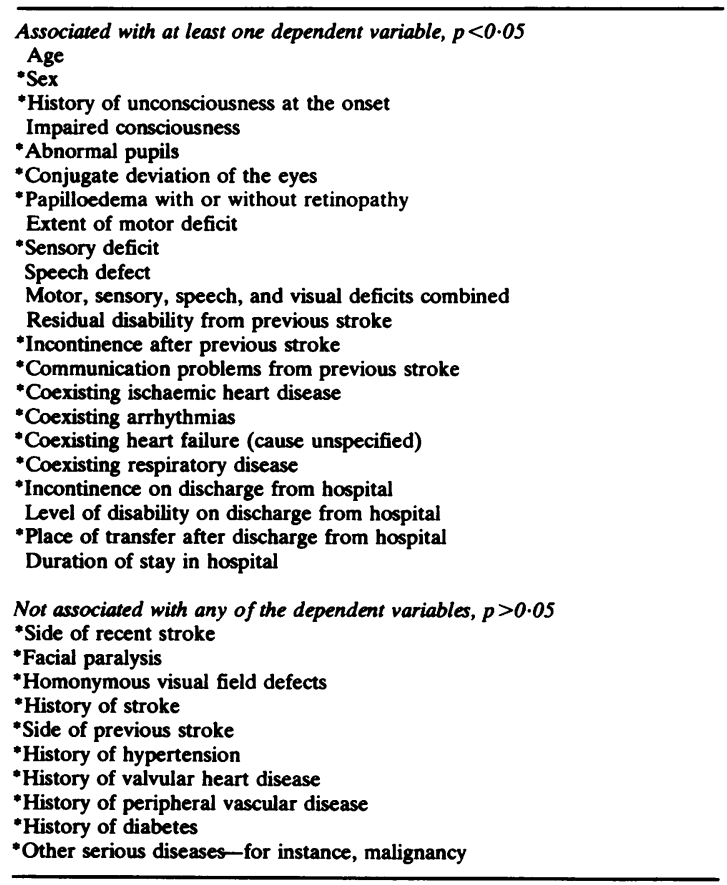

"Dichotomous variables.

Most of the 32 variables chosen for the analyses were given only two values - the presence or absence of a disease or a sign, irrespective of the type, degree, or grade (table 1). Level of consciousness as assessed at clinical examination on the day of stroke was graded on an ascending six-point scale-conscious, drowsy, confused, unresponsive, unconscious, and comatose. This scale is referred to as "impairment of consciousness." For all patients, including those not examined on the day of the stroke itself, "history of unconsciousness at the onset" was recorded simply as present or absent. The extent of motor deficit in the limbs, irrespective of the severity of weakness, was graded on a four-point scale-no weakness, weakness in one limb, weakness in both limbs on one side, and weakness in at least one limb on each side-for example, in a patient who already had one side affected by a previous stroke. Facial weakness and sensory deficit were graded as present or absent, irrespective of the type, extent, and side affected. Visual field defect was defined as the presence or absence of homonymous hemianopia or quadrantanopia on either side. Speech defect was graded on a three-point scale-normal speech, mild dysphasia, and severe dysphasia or aphasia. Motor, sensory, speech, and visual defects were also combined into a score consisting of one point for motor weakness of any severity in each affected limb, one point for sensory loss of any type or extent, one point for any type or degree of speech defect, and one point for any homonymous visual field defect. A hemiplegic patient with sensory loss and speech and visual field defects was thus given five points. Rankin's grades ${ }^{10}$ were used to classify the level of residual disability from previous and recent stroke on a three-point scale-none or slight (grades I-II), moderate (grade III), and severe (grades IV-V). This classification was based on mobility and ability in self-care. The level of disability on Rankin's scale correlates well with other objective methods of assessment-for example, the activities of daily living index. ${ }^{14}$ Incontinence was included as a separate variable.

Dates of birth, onset of stroke, admission to and discharge from the hospital or of death, the extent of motor deficit, and the side of the lesion were known for all 900 patients. The level of disability, state of continence, and communication problems on discharge and the place or agency to which the patient was discharged were also known or could be inferred for all the patients discharged alive. The medical history or other findings on clinical examination were not recorded in the casenotes of a few patients; in these cases it was assumed that the diseases or the signs were not present. Some of the patients were admitted to the hospital and examined several days after the onset of stroke so that the level of consciousness on the day of the stroke was not known. Those who died without regaining full consciousness could not be assessed for speech and visual field defects.

The outcome (dependent) variables were three-week survival, one-year survival, and the level of disability on discharge; the latter was also used as an independent variable for subsequent mortality. Firstly, each independent variable was separately related to each of the three dependent variables. Twently-two variables were found to be associated with a least one of the outcome variables (see table 1) and were then included in a series of linear multiple regression analyses using the step-up method. ${ }^{15}$

\section{Results}

In the five-year period a total of 900 patients (405 men and 495 women) were admitted with a recent stroke as defined; 568 were admitted on the day of the stroke, 284 the day after the stroke, and 48 had a stroke while in hospital for some other illness. The mean age of the men was 69.6 (range 35-95) and that of the women 75.5 (range 42-102, apart from one women of 27). A history of cardiovascular disease(s) 
Table 2 Predictors of mortality in 900 patients with stroke

\begin{tabular}{|c|c|c|c|c|c|}
\hline $\begin{array}{l}\text { Predictors of death } \\
\text { within three weeks }\end{array}$ & $\begin{array}{l}\text { Regression } \\
\text { coefficient }\end{array}$ & $t$ value & $\begin{array}{l}\text { Predictors of death } \\
\text { within one year }\end{array}$ & $\begin{array}{l}\text { Regression } \\
\text { coefficient }\end{array}$ & $t$ value \\
\hline $\begin{array}{l}\text { History of unconsciousness } \\
\text { at onset }\end{array}$ & 0.2190 & $6 \cdot 68^{* * *}$ & Combined neurological deficits & $0 \cdot 1072$ & $6 \cdot 07^{* * *}$ \\
\hline $\begin{array}{l}\text { Combined neurological deficits } \\
\text { Conjugate deviation of eyes }\end{array}$ & $\begin{array}{l}0.0969 \\
0.1683\end{array}$ & $\begin{array}{l}6 \cdot 28 * * * \\
5 \cdot 09^{* * *}\end{array}$ & $\begin{array}{l}\text { Increasing age } \\
\text { History of unconsciousness } \\
\text { at onset }\end{array}$ & $\begin{array}{l}0.0103 \\
0.1709\end{array}$ & $\begin{array}{l}7 \cdot 20^{* * *} \\
4 \cdot 55^{* * *}\end{array}$ \\
\hline $\begin{array}{l}\text { Increasing age } \\
\text { Sensory deficit } \\
\text { Abnormal pupils } \\
\text { Speech defect (if tested) }\end{array}$ & $\begin{array}{l}0.0053 \\
0 \cdot 1000 \\
0.0756 \\
0.0558\end{array}$ & $\begin{array}{l}4 \cdot 23^{* * *} \\
2 \cdot 88^{* *} \\
2 \cdot 17^{*} \\
3 \cdot 15^{* *}\end{array}$ & $\begin{array}{l}\text { Sensory deficit } \\
\text { Abnormal pupils } \\
\text { Conjugate deviation of eyes }\end{array}$ & $\begin{array}{l}0 \cdot 1411 \\
0 \cdot 1150 \\
0 \cdot 1007\end{array}$ & $\begin{array}{l}3 \cdot 55^{* * *} \\
2 \cdot 88^{* *} \\
2 \cdot 66^{* *}\end{array}$ \\
\hline \multicolumn{3}{|c|}{ Multiple $\mathrm{r}=0.4701^{* * *}$} & \multicolumn{3}{|c|}{ Multiple $r=0.4247^{* * *}$} \\
\hline
\end{tabular}

Table 3 Predictors of mortality in 568 patients examined on the day of stroke

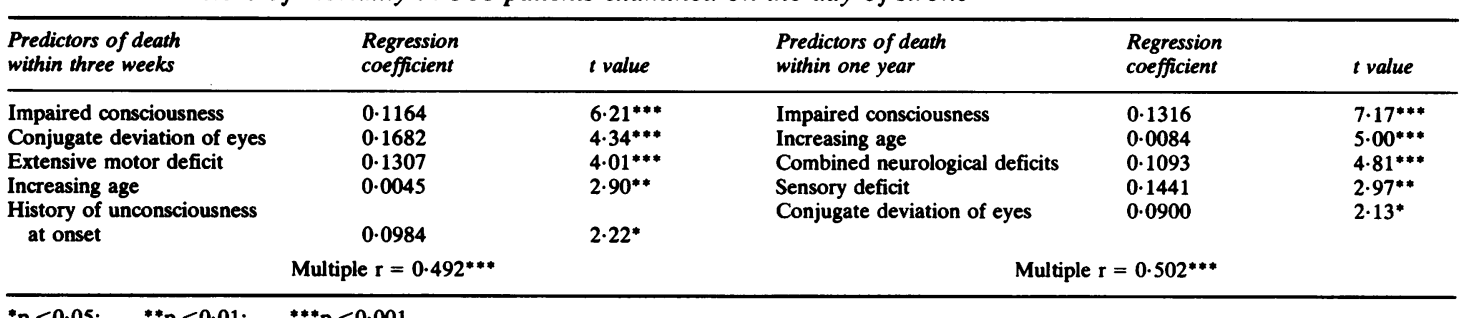

*p $<0.05 ; \quad$ **p $<0.01 ; \quad{ }^{* * *} \mathrm{p}<0.001$.

was recorded for 482 patients; 226 had had previous cerebrovascular disease. Of the 173 patients with a history of at least one previous stroke, 85 had moderate to severe disability, in terms of the Rankin index, before sustaining the stroke for which they were admitted.

The recent stroke affected the left hemisphere in 450 patients, the right hemisphere in 420 , and brain stem in 48. Of the total of 900 patients, $180(20 \%)$ had abnormal pupillary reactions; 262 (29\%) papilloedema with or without other signs of retinopathy; $173(19 \%)$ conjugate deviation of the eyes; $565(63 \%)$ facial weakness; $848(94 \%)$ motor weakness in one or more limbs; and 297 (33\%) some !sensory loss. Of the 726 patients whose visual fields were assessed, 171 (23\%) were found to have homonymous defects. Seventy patients could not be tested for speech defect; out of the remaining $\mathbf{8 3 0}$ patients, $316(38 \%)$ had normal speech, there was evidence of some disturbance in speech in 499 patients $(60 \%)$, and in $55(7 \%)$ the assessment was inconclusive.

A total of 548 patients were discharged alive, 248 (45\%) with slight or no physical disability, $229(42 \%)$ with moderate, and $71(13 \%)$ with severe disability; $458(84 \%)$ went home and the remaining $90(16 \%)$ were transferred to other hospitals, mostly for long istay. Of the 900 patients, 248 (28\%) died within three weeks and $437(49 \%)$ within a year. Cerebrovascular disease was the certified cause in $85 \%$ of the deaths.

As expected, the univariate analyses showed that many of the independent variables were correlate with each other. A full correlation matrix (available on request) showed that each of the 22 independen variables significantly associated with the dependent5. variable(s) (see table 1) was also correlated with at least four other predictors.

The predictors of mortality and disability are listed in tables $2-5$ in the order in which they were selected by the multiple regression analyses. Table 2 shows the predictors of death within three weeks and within one year after stroke in all 900 patients. For these analyses, impairment of consciousness, duration of stay in hospital, level of disability, and state of continence on discharge were not included as they were not applicable to all 900 patients (see methods). When impairment of consciousness was included in the regression for the 568 patients examined in the hospital on the day of stroke (table 3 ) it contributed most to the prediction, replacing the history of unconsciousness at the onset and combined

Table 4 Predictors of death within one year from onset of stroke in 548 patients who were discharged alive

\begin{tabular}{lcc}
\hline Predictors & $\begin{array}{c}\text { Regression } \\
\text { coefficient }\end{array}$ & $t$ value \\
\hline Increasing age & $0 \cdot 0031$ & $2 \cdot 03^{*}$ \\
Sensory deficit & $0 \cdot 0800$ & $2 \cdot 29^{*}$ \\
Severe disability & $0 \cdot 0518$ & $2 \cdot 04^{*}$ \\
& Multiple $\mathrm{r}=0.2183^{* * *}$ & \\
\hline
\end{tabular}

$* p<0.05 ; \quad * * * p<0.001$. 
Table 5 Predictors of physical disability in 548 patients

\begin{tabular}{|c|c|c|}
\hline Predictors & $\begin{array}{l}\text { Regression } \\
\text { coefficient }\end{array}$ & $t$ value \\
\hline $\begin{array}{l}\text { Combined neurological deficits } \\
\text { Increasing age } \\
\text { Incontinence } \\
\text { Disability from previous stroke } \\
\text { Impaired consciousness } \\
\text { Female sex } \\
\text { Extensive motor deficit }\end{array}$ & $\begin{array}{l}0 \cdot 1470 \\
0 \cdot 0085 \\
0 \cdot 7413 \\
0 \cdot 2729 \\
0 \cdot 0952 \\
0 \cdot 1268 \\
0 \cdot 1249\end{array}$ & $\begin{array}{l}4 \cdot 65^{* * *} \\
3 \cdot 29^{* * *} \\
3 \cdot 31^{* * *} \\
2 \cdot 89^{* *} \\
2 \cdot 90^{* *} \\
2 \cdot 28^{*} \\
2 \cdot 15^{*}\end{array}$ \\
\hline \multicolumn{3}{|c|}{ Multiple $\mathrm{r}=0.429^{* * *}$} \\
\hline
\end{tabular}

neurological deficits as the leading predictor of both three-week and one-year mortality. Table 4 shows the predictors of death within a year after stroke in the 548 patients who were discharged alive. The duration of stay in hospital, the level of disability, and the state of continence on discharge were included in this analysis. Impairment of consciousness made no additional contribution in those examined on the day of stroke and discharged alive.

Table 5 shows the predictors of disability in the 548 patients discharged alive.

Tables 2-5 also show multiple correlation coefficients for the associations between the combination of predictor variables and outcome. The strength of these associations can be illustrated by the proportion of patients correctly predicted as likely to die or to survive. Using the regression coefficients in table 2 to derive a score for each patient, death or survival within three weeks, for example, could be correctly predicted for $73 \%$ of all the 900 patients.

\section{Discussion}

The accurate prediction of survival and functional recovery is likely to be of value both in planning the management of individual patients and the organisation of the relevant health and social services, especially as information grows on the effectiveness of specific measures such as the use of special stroke units ${ }^{16}$ and the value of outpatient rehabilation. ${ }^{17}$ It will also be possible to design future trials on selected groups of patients whose outcome is known. These groups might be those likely to do well or likely to do badly, depending on whether the particular purpose of the trial is to speed recovery in those with a good prognosis, or to alter prognosis in those at specially high risk of death or disability.

The analyses presented here were not intended to show any hitherto unknown characteristics influencing the outcome after stroke. The main object was to identify those characteristics making an independent contribution to predicting outcome, after allowing for numerous intercorrelations. Of the 32 characteristics evaluated in univariate analyses, 22 appeared to have some predictive values (table 1). In the multiple regression analyses, however, only 10 were independently related to prognosis for survival and seven for disability. Most of the characteristics with independent predictive value were common to the six sets of predictors shown in tables 2-5.

Older patients who are unconscious at the onset of the stroke, have multiple neurological deficits (particularly sensory loss), abnormal pupils, and conjugate deviation of the eyes are more likely to die within a year than those without these characteristics (table 2). Those who, in addition, have extensive motor deficits are more likely to die within the first three weeks (table 3 ). The general similarity between the predictors of death at three weeks and a year is not surprising, as over half those who died within a year had died within three weeks. Those who are discharged from hospital alive are likely to die within a year if they are old and have sensory loss and severe physical disability. So far as mortality is concerned, sex made no independent contribution; the apparent sex difference in the univariate analyses is due to the relation between female sex and several variables-impaired consciousness or history of unconsciousness at the onset, age, the level of disability, and incontinence-associated with high mortality. Nor did the presence of visual field defects or vascular disease other than stroke itself make an independent contribution. Older incontinent patients, particularly women who lose consciousness at the onset of the stroke, have extensive motor deficits in combination with other neurological deficits, and residual disabilities from previous strokes are more likely to be disabled on discharge from hospital. These findings (table 5) are not surprising, because physical disability in stroke is largely due to neurological deficits. It has been suggested that contractures, body image agnosia, anosognosia, apraxia, spatial disorientation, and psychological factors also adversely affect functional recovery after stroke. ${ }^{121318-20}$

It should be emphasised that the results described are based on the examination of routine case notes in which details - were not recorded in a standard manner. Some assumptions had to be made about missing data, particularly for those who died soon after admission to hospital. For these reasons, the true strength of the associations between predictors and outcome has probably been underestimated, perhaps quite considerably. The predictors established in this study should be validated using data collected and recorded according to predetermined criteria.

We conclude that it is already possible from 
routinely collected clinical data to make useful forecasts not only about mortality but also about disability after stroke and that the accuracy of these forecasts can probably be improved still further.

Requests for reprints to; Dr T W Meade, MRC Epidemiology and Medical Care Unit, Northwick Park Hospital, Harrow HA1 3UJ, Middlesex.

\section{References}

${ }^{1}$ Marquardsen J. The natural history of acute cerebrovascular disease: a retrospective study of 769 patients. Acta Neurol Scand 1969; 45,supp 38-137.

${ }^{2}$ Anderson E. Sensory impairment in hemiplegia. Arch Phys Med Rehabil 1971; 52: 293-7.

${ }^{3}$ Lehman JF, DeLateur BJ, Fowler RS, et al. Stroke rehabilitation: outcome and prediction. Arch Phys Med Rehabil 1975; 56: 383-9.

${ }^{4}$ Issacs B, Marks R. Determinants of outcome of stroke rehabilitation. Age and Ageing 1978; 2: 139-49.

${ }^{5} \mathrm{Gibson}$ CJ. Epidemiology and patterns of care of stroke patients. Arch Phys Med Rehabil 1974; 55: 398-403.

${ }^{6}$ Granger CV, Geer DS, Liset E, Coulombe J, O'Brien E. Measurement of outcomes of care for stroke patients. Stroke 1975; 6: 34-41.

${ }^{7}$ Miller AS, Miyamoto AT. Computed tomography: its potential as a predictor of functional recovery following stroke. Arch Phys Med Rehabil 1979; 60: 108-9.
${ }^{8}$ Oxbury JM, Greenhall RCD, Grainger KMR. Predicting the outcome of stroke: acute stage after cerebral infarction. Br Med J 1975; iii: 125-7.

${ }^{9}$ Hearer A. Visual field defects and the prognosis of stroke patients. Stroke 1973; 4: 163-8.

${ }^{10}$ Rankin J. Cerebral vascular accidents in patients over the age of 60: II-Prognosis. Scot Med J 1975; 2: 200-15.

${ }^{11}$ Rabkin SW, Mathewson FAL, Tate RB. The relation of blood pressure to stroke prognosis. Ann Intern Med 1978; 89: 15-20.

${ }^{12}$ Bourestom NC. Predictors of long-term recovery in cerebrovascular disease. Arch Phys Med Rehabil 1967; 45: 415-9.

${ }^{13}$ Anderson TP, Bourestom NC, Greenberg FR, Hilyard VG. Predictive factors in stroke rehabilitation. Arch Phys Med Rehabil 1974; 55: 545-53.

${ }^{14}$ Sheikh K, Smith DS, Meade TW, Goldenberg E, Brennan PJ, Kinsella G. Repeatability and validity of a modified activities of daily living (ADL) index in studies of chronic disability. International Rehabilitation Medicine 1979; 1: 51-8.

${ }^{15}$ Draper N, Smith H. Applied regression analyses. New York: Wiley, 1966: 163-95.

${ }^{16}$ Garraway WM, Akhtar AJ, Prescott RJ, Hockey L. Management of acute stroke in the elderly: preliminary results of a controlled trial. $\mathrm{Br}$ Med J 1980; 280: 1040-3.

${ }^{17}$ Smith DS, Goldenberg E, Ashburn A, et al. Remedial therapy after stroke: a randomised controlled trial. $\mathrm{Br}$ Med J 1981; 282: 517-20.

${ }^{18}$ Hurwitz LJ, Adams GF. Rehabilitation of hemiplegia: indices of assessment and prognosis. $\mathrm{Br}$ Med J 1972; i: 94-8.

${ }^{19}$ Hyman MD. Social psychological determinants of patients' performance in stroke rehabilitation. Arch Phys Med Rehabil 1972; 53: 217-26.

${ }^{20}$ Jimenez J, Keltz E, Stein MC, White MME. Evaluation of stroke disability. Canadian Med Assoc J 1976; 114: 614-6. 